\author{
Marquette University \\ e-Publications@Marquette
}

Mechanical Engineering Faculty Research and

Publications

Mechanical Engineering, Department of

2012

\title{
Are Posture Data from Simulated Tasks Representative of Field Conditions? Case Study for Overhead Electric Utility Workers
}

\author{
Cristiane Shinohara Moriguichi \\ Federal University of São Carlos \\ Leticia Carnaz \\ Federal University of São Carlos \\ Luiz Carlos de Miranda Jr \\ State University of Campinas \\ Richard W. Marklin \\ Marquette University, richard.marklin@marquette.edu \\ Helenice Jane cote Gil Coury \\ Federal University of São Carlos
}

Follow this and additional works at: https://epublications.marquette.edu/mechengin_fac

Part of the Mechanical Engineering Commons

\section{Recommended Citation}

Moriguichi, Cristiane Shinohara; Carnaz, Leticia; de Miranda, Luiz Carlos Jr; Marklin, Richard W.; and cote Gil Coury, Helenice Jane, "Are Posture Data from Simulated Tasks Representative of Field Conditions? Case Study for Overhead Electric Utility Workers" (2012). Mechanical Engineering Faculty Research and Publications. 28.

https://epublications.marquette.edu/mechengin_fac/28 
Marquette University

e-Publications@Marquette

\section{Mechanical Engineering Faculty Research and Publications/College of Engineering}

This paper is NOT THE PUBLISHED VERSION; but the author's final, peer-reviewed manuscript. The published version may be accessed by following the link in the citation below.

Ergonomics, Vol. 55, No. 11 (2012): 1382-1394. DOI. This article is (C) Taylor \& Francis and permission has been granted for this version to appear in e-Publications@Marquette. Taylor \& Francis does not grant permission for this article to be further copied/distributed or hosted elsewhere without the express permission from Taylor \& Francis.

\section{Are Posture Data from Simulated Tasks Representative of Field Conditions? Case Study for Overhead Electric Utility Workers}

Cristiane Shinohara Moriguchi

Department of Physical Therapy, Federal University of Saõ Carlos, Saõ Carlos, Saõ Paulo, Brazil Letícia Carnaz

Department of Physical Therapy, Federal University of Saõ Carlos, Saõ Carlos, Saõ Paulo, Brazil Luiz Carlos Miranda Júnior

Center of Technological

Higher Education, State University of Campinas, Campinas, Saõ Paulo, Brazil

Richard William Marklin

Department of Mechanical Engineering, Marquette University, Milwaukee, Wisconsin

Helenice Jane Cote Gil Coury

Department of Physical Therapy, Federal University of Saõ Carlos, Saõ Carlos, Saõ Paulo, Brazil 


\begin{abstract}
Many ergonomics studies are conducted in laboratory-simulated work environments to assess risks for the development of musculoskeletal disorders under more controlled conditions. However, the simulated conditions could be of questionable validity with respect to reproduction of field conditions involving risk factors. The objective of this study was to verify whether the postures recorded for neck extension/flexion and upper arm elevation of overhead electric utility workers in a simulated environment were similar to those recorded in a field environment. Of the three frequently performed tasks analysed, two presented similar exposure in both conditions. However, differences were identified for a more complex task (relay replacement). These results suggest that simulated tasks may be more representative for more standardised tasks. This may indicate that researchers investigating risks should avoid simplifying complex tasks when reproducing field posture exposure in laboratories, since omitting extra subtasks may lead to an inaccurate reproduction of field exposure.
\end{abstract}

\title{
Practitioner Summary
}

Studies comparing results from field and simulated environments are necessary to evaluate to what degree postural exposure reproduced in laboratory is representative of the exposure occurring in real work situations. This is particularly relevant for tasks involving training in simulated environment due to safety constraints.

\section{Keywords}

work-related musculoskeletal disorders, laboratory simulation studies, postural exposure, inclinometers

\section{Introduction}

Guidelines and literature reviews have already demonstrated the high validity of direct measurements performed at the workplace to assess exposure to risk factors for the development of musculoskeletal disorders (Winkel and Westgaard 1992, Winkel and Mathiassen 1994, David 2005). However, many ergonomics studies are conducted in laboratories and utilise simulated workplace environment (Chung and Shorrock 2011) to evaluate either risk factors (Oliveira et al. 2011) or intervention results (Rodack and Vieira 2010). The reconstruction of work environments in the laboratory allows researchers to evaluate and control variables of interest using complex measurement systems, to reduce variance of response variables and to increase the power of statistical tests (Westgaard and Winkel 1997, Scott and Renz 2006, van Dieën et al. 2010).

Simulated environments also become a consideration when research in field environment is not feasible or risky for worker safety (Petruzzello et al. 2009). One such case involves overhead workers in the electrical energy industry, while working outdoors at great heights and under different weather conditions and requiring qualified personnel to handle the energised overhead lines (Salmon et al. 2008). In addition, strict safety regulations to prevent acute injuries may also interfere with data collection equipment, since the use of portable equipment could expose them to risk of electrical shock and burns. On the other hand, the reported prevalence of musculoskeletal symptoms (Moriguchi et al. 2009), the high number of injuries and workdays lost (EPRI 2011), the exposure to awkward postures (Moriguchi et al. 2011) and the forceful tasks involved in overhead electric utility work (Seeley and Marklin 2003) highlight the need for further study of overhead workers in order to prevent injuries and musculoskeletal disorders.

Small differences between simulated and field conditions could result in a different understanding of the data (van Dieën et al. 2010) and misinterpretation of the events being studied. As such, the simulated conditions could be questionable regarding their validity for reproducing field conditions (Scott and Renz 2006) and, consequently, the biomechanical load recorded in the simulated environment. Thus, the objective of this study 
was to verify whether the postures recorded for neck extension/flexion and upper arm elevation of overhead electric utility workers in a simulated environment were similar $\left(\mathrm{H}_{0}\right)$ to those recorded in a field environment or if one of the conditions produces wider amplitudes than the other $\left(\mathrm{H}_{1}\right)$.

\section{Material and methods}

\subsection{Subjects}

Right-handed male overhead workers from an electrical energy industry in Brazil participated in the study. The subjects were split into two groups. One group $(N=12)$ performed the tasks in a simulated environment that was not energised (age $43 \pm 8$ years; weight $86 \pm 17 \mathrm{~kg}$, height $1.75 \pm 0.08 \mathrm{~m}$, experience on the job $16 \pm 6$ years). The other group ( $N=12$ ) performed the same tasks, but in the field during their normal daily work (age $37 \pm 7$ years, weight $77 \pm 9 \mathrm{~kg}$, height $1.77 \pm 0.07 \mathrm{~m}$, experience on the job $12 \pm 8$ years). A sample of 12 recordings was made for each group, with one subject participating in both the simulated and field conditions.

All participants were informed about the procedures involved in the study and gave their written informed consent. The study was approved by the Research Ethics Committee of the University.

\subsection{Data collection}

Neck extension/flexion angles and upper arm elevation angles were evaluated with inclinometers featuring triaxial accelerometers that measured the angle of the body segment in relation to a vertical gravity line. Data were sampled at $20 \mathrm{~Hz}$ using a data logger (Logger Teknologi HB ${ }^{\circledR}$, Åkarp, Sweden). Four inclinometer sensors were attached to the workers at the head, upper back and upper arms. The head sensor was attached to the front side of the helmet, the upper back sensor was attached to the right of the C7 vertebra and the upper arm sensors were attached just below the right and left deltoid tendon insertions. Reference and direction positions were recorded for all sensors to build the coordinate system for angle calculation (Hansson et al. 2001). For the head and upper back, the reference position was set while the subject stood and the direction position was set while the subject was seated with his neck and trunk flexed. For the upper arms, the reference position was set with the subject seated and the arm hanging relaxed and perpendicular to the floor while holding a $2 \mathrm{~kg}$ dumbbell. The direction position was set at $90^{\circ}$ of upper arm elevation with the subject in the standing position. These methods and procedures were performed according to previous studies (Hansson et al. 2006, 2010, Moriguchi et al. 2011). Neck postures were calculated as the difference between the corresponding measures of the head/helmet and upper back (Hansson et al. 2006). For neck postures, negative values denoted extension angles and positive values denoted flexion angles. It was not possible to distinguish whether the upper arms were abducted or flexed because the inclinometers measured the angle of the arms relative to gravity, thus these movements are referred to as 'elevation'.

The same data collection procedures were performed by the same researchers in both the groups. Video was also recorded for both conditions to allow identification of visual differences between the simulated and field conditions and was used only to describe the tasks more precisely.

\subsection{Task descriptions}

Three overhead tasks frequently performed by electric utility workers were evaluated in a simulated and in a field environment ( Figure 1). Figure 1(a,b) shows photoelectric relay replacement (relay replacement) in simulated and field environments, which consisted of changing the photo relay of a public lamppost, Figure $1(c, d)$ shows switching a consumer unit on and off (consumer connection/disconnection) in simulated and field environments, i.e. initiating or terminating electrical service to a specific consumer by connecting or disconnecting the electrical wires; Figure $1(e, f)$ shows light bulb replacement in simulated and field environments, which consisted of changing the bulb in a public lamppost. 
Figure 1. Electrical overhead workers performing three tasks in simulated and field environments. (a) Relay replacement task in simulated environment. (b) Relay replacement task in field environment. (c) Consumer connection/disconnection in simulated environment. (d) Consumer connection/disconnection in field environment. (e) Bulb replacement in simulated environment. (f) Bulb replacement in field environment.

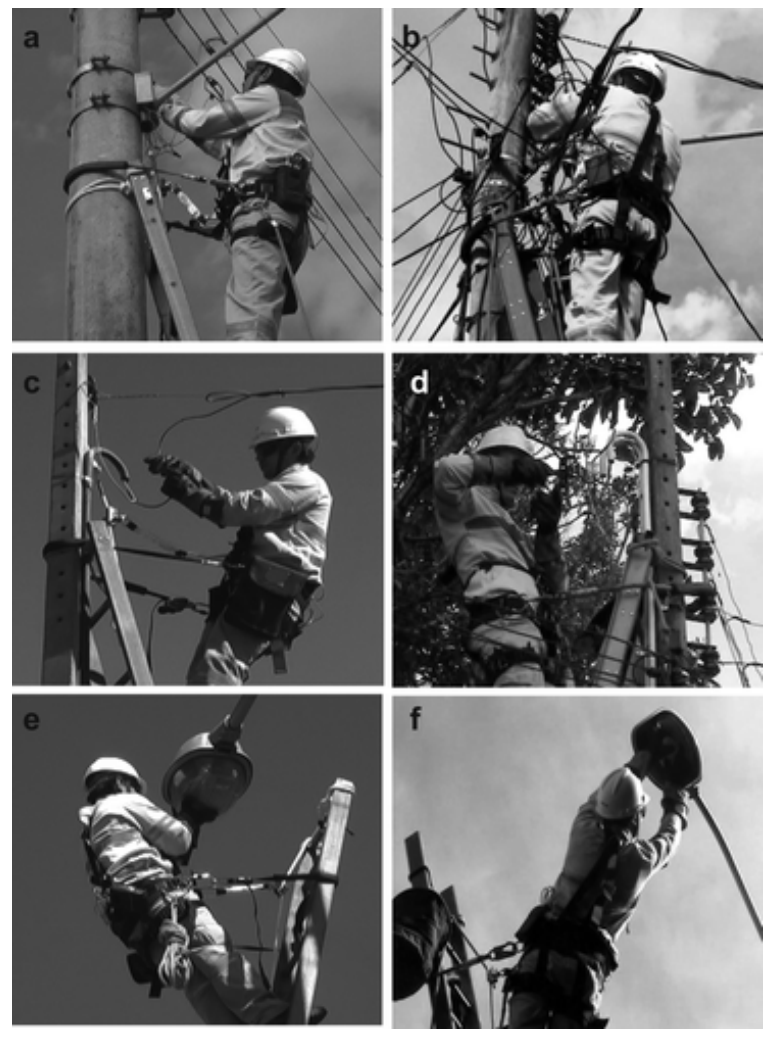

In the simulated environment, the task conditions were the same for all workers and were planned and controlled by the researchers. The simulated conditions were performed at the power company's technological centre, which is used for worker training.

In the field environment, electrical workers received their daily job orders before they left the service centre to perform field work. The three field tasks were identified by the technician responsible for company logistics based on consumer requests. The technician selected the tasks without any other instruction about the conditions in which the tasks would be performed. After receiving the orders, the worker collected the material and equipment necessary for performing the tasks and left the service centre in the company truck. At the site where the task was performed, the worker followed the standard safety instructions for each task, including inspecting the local conditions, indicating where the task would be performed, positioning the ladder and preparing the materials to carry out the task (relay or bulb replacement, consumer connection or disconnection). These initial tasks were not considered in the comparison between simulated and field conditions.

Detailed descriptions of the three analysed tasks and the setup in the simulated and field environments are presented in Table 1. The subtasks involved in each task (relay replacement, consumer connection/disconnection and bulb replacement) were separated into 'preliminary subtasks' (corresponding to the initial subtasks performed to position tools/equipment at the work site), 'specific subtasks' (corresponding to the subtasks inherent to each task) and 'final subtasks' (corresponding to the subtasks performed to collect tools/equipments after finishing the specific subtasks). These subtasks presented a chronological order during the task performance: workers started the tasks performing the preliminary subtasks and then performed the 
specific subtasks and ended performing the final subtasks. The 'extra subtasks' (non-inherent subtasks), also presented at Table 1, correspond to subtasks performed simultaneously to the specific subtasks in the field environment but not in simulated environment. The only exception was the subtask of covering the wires with electric isolating material, which is a preliminary subtask performed in the field but not in the simulated. For both conditions, the number of subjects who performed each subtask was recorded in order to identify their frequency in simulated and field environments. 
Table 1. Relay replacement, consumer connection/disconnection and bulb replacement task descriptions.

\begin{tabular}{|c|c|c|c|c|c|c|c|c|}
\hline $\begin{array}{c}\text { Number of subjects for each } \\
\text { performed subtasks }\end{array}$ & & & & & & & & \\
\hline Relay replacement & & & Consumer connection/disconnection & & & Bulb replacement & & \\
\hline \multicolumn{9}{|l|}{ Preliminary subtasks } \\
\hline $\begin{array}{l}\text { Climb the ladder and attach } \\
\text { the lanyard to the public pole } \\
\text { and adjust the lanyard }\end{array}$ & $N=12$ & $N=12$ & $\begin{array}{l}\text { Climb the ladder and attach the lanyard } \\
\text { to the public/consumer pole and adjust } \\
\text { the lanyard }\end{array}$ & $N=12$ & $N=11$ & $\begin{array}{l}\text { Climb the ladder and attach the } \\
\text { lanyard to the ladder and adjust } \\
\text { the lanyard }\end{array}$ & $N=12$ & $N=11$ \\
\hline $\begin{array}{l}\text { Tie the top of ladder into the } \\
\text { pole using a rope }\end{array}$ & $N=1$ & $N=12$ & $\begin{array}{l}\text { Tie the top of ladder into the pole using } \\
\text { a rope }\end{array}$ & $N=3$ & $N=11$ & & & \\
\hline $\begin{array}{l}\text { Pull a rope to suspend a bag } \\
\text { with equipments and bind the } \\
\text { bag into the ladder/pole }\end{array}$ & $N=2$ & $N=12$ & $\begin{array}{l}\text { Pull a rope to suspend a bag with } \\
\text { equipments and bind the bag into the } \\
\text { ladder/pole }\end{array}$ & $N=7$ & $N=11$ & $\begin{array}{l}\text { Pull a rope to suspend a bag } \\
\text { with equipments and bind the } \\
\text { bag into the ladder }\end{array}$ & $N=1$ & $N=7$ \\
\hline \multicolumn{9}{|l|}{ Specific subtasks } \\
\hline $\begin{array}{l}\text { Remove the relay from its } \\
\text { base and save it in the fanny } \\
\text { pack attached to worker waist } \\
\text { or in the bag }\end{array}$ & $N=12$ & $N=12$ & $\begin{array}{l}\text { Disconnect and/or reconnect the } \\
\text { connection between consumer and } \\
\text { company cables }\end{array}$ & $N=12$ & $N=11$ & $\begin{array}{l}\text { Open and close luminaire } \\
\text { protective cover }\end{array}$ & $N=12$ & $N=5$ \\
\hline \multirow[t]{2}{*}{$\begin{array}{l}\text { Get a new relay in the fanny } \\
\text { pack or in the bag and attach it } \\
\text { in the relay base }\end{array}$} & $N=12$ & $N=12$ & & & & $\begin{array}{l}\text { Remove the bulb from the } \\
\text { luminaire and save it in the } \\
\text { fanny pack attached to worker } \\
\text { waist or in the bag }\end{array}$ & $N=12$ & $N=11$ \\
\hline & & & & & & $\begin{array}{l}\text { Get a new bulb in the fanny } \\
\text { pack or in the bag and attach } \\
\text { the bulb in the luminaire }\end{array}$ & $N=12$ & $N=11$ \\
\hline \multicolumn{9}{|l|}{ Final subtasks } \\
\hline $\begin{array}{l}\text { Release the bag from the } \\
\text { ladder and down the bag }\end{array}$ & $N=2$ & $N=11$ & $\begin{array}{l}\text { Release the bag from the ladder and } \\
\text { down the bag }\end{array}$ & $N=7$ & $N=11$ & $\begin{array}{l}\text { Release the bag from the ladder } \\
\text { and down the bag }\end{array}$ & $N=1$ & $N=6$ \\
\hline $\begin{array}{l}\text { Release the rope holding the } \\
\text { top of the ladder against the } \\
\text { pole }\end{array}$ & & $N=10$ & $\begin{array}{l}\text { Release the rope holding the top of the } \\
\text { ladder against the pole }\end{array}$ & $N=2$ & $N=11$ & & & \\
\hline $\begin{array}{l}\text { Release the lanyard and } \\
\text { climbed down }\end{array}$ & $N=12$ & $N=12$ & Release the lanyard and climbed down & $N=12$ & $N=11$ & $\begin{array}{l}\text { Release the lanyard and climbed } \\
\text { down }\end{array}$ & $N=12$ & $N=11$ \\
\hline \multicolumn{9}{|l|}{ Extra subtasks } \\
\hline Test the relay & & $N=10$ & & & & & & \\
\hline Connect wires & & $N=8$ & & & & & & \\
\hline Analysis & & $N=7$ & Analysis & & $N=6$ & Analysis & & $N=1$ \\
\hline Wait for equipments & & $N=3$ & Wait for equipments & & $N=4$ & Wait for equipments & & $N=1$ \\
\hline $\begin{array}{l}\text { Repeated one of the specific } \\
\text { subtasks }\end{array}$ & & $N=3$ & Repeated one of the specific subtasks & & $N=9$ & & & \\
\hline
\end{tabular}




\begin{tabular}{|c|c|c|c|c|c|c|c|c|}
\hline Replace relay base & & $N=3$ & & & & & & \\
\hline \multirow[t]{3}{*}{$\begin{array}{l}\text { Cover wires with electric } \\
\text { isolating material }\end{array}$} & & $N=1$ & $\begin{array}{l}\text { Cover wires with electric isolating } \\
\text { material }\end{array}$ & & $N=1$ & & & \\
\hline & & & Strip cables & & $N=6$ & & & \\
\hline & & & Use isolating tape & & $N=1$ & & & \\
\hline \multicolumn{9}{|l|}{ Setup description } \\
\hline \multirow[t]{2}{*}{$\begin{array}{l}\text { Ladder already tied to the } \\
\text { pole }\end{array}$} & $N=12$ & $N=0$ & Ladder already tied to the pole & $N=12$ & $N=0$ & & & \\
\hline & & & Ladder positioned on the consumer pole & $N=12$ & $N=3$ & $\begin{array}{l}\text { Pole disposed to the right of the } \\
\text { worker }\end{array}$ & $N=12$ & $N=9$ \\
\hline $\begin{array}{l}\text { Workstation in front of } \\
\text { worker at shoulder level }\end{array}$ & $N=12$ & $N=10$ & $\begin{array}{l}\text { Workstation in front of worker at } \\
\text { shoulder level }\end{array}$ & $N=12$ & $N=4$ & $\begin{array}{l}\text { Workstation in front of worker } \\
\text { at head level }\end{array}$ & $N=12$ & $N=2$ \\
\hline
\end{tabular}

Note: The number of overhead workers that performed each of the subtasks during simulated (S) and field (F) environments are presented for the three tasks. The setup descriptions of simulated and field environments are also shown. 
The preliminary and final subtasks are common to the relay replacement, consumer connection/disconnection and bulb replacement tasks (Table 1). To perform these subtasks in the simulated environment, the workers wore a fanny pack around their waist to carry the equipment necessary for the task. However, in the field, most workers preferred a tool bag, which was bigger and could accommodate more equipment. Thus, in the field, the workers needed to hoist and lower the tool bag. For the relay replacement and consumer connection/disconnection tasks, the worker also attached and released the top of the ladder to the pole while in the field, although this procedure was not performed in the simulated environment because the ladder was already fixed.

The specific subtasks were very similar between simulated and field conditions for two of the tasks: the only exception being the bulb replacement task performed in the field, since not all of the streetlights were equipped with protective covers. Thus, the subtasks of opening and closing the streetlight cover, depicted in Figure 1(e), were not performed by all workers in the field.

Extra subtasks were observed for the three tasks performed in the field and were more frequent for relay replacement. The most commonly performed extra subtask in the field occurred in the relay test and consisted of checking whether the bulb functioned after changing the relay. This subtask was not performed since there was no electrical current in the simulated environment due to safety reasons. Other extra subtasks frequently performed in the field but not in the simulated environment were wire reconnection and worksite analysis.

The simulated setup was better ergonomically due to the fact that the activities could be performed in front of the workers (Figure 1(a,c,e)). However, in the field, this was not always possible (Figure 1(f)). The simulated consumer connection/disconnection task was performed at a consumer pole, usually a shorter residential pole. However, in the field, this task could also occur at a public pole, which is higher than the consumer pole. Moreover, more wires were usually attached to the public pole (Figure 1(b)), making the task more complex.

The order of the tasks was randomised for the simulated and field environments and the same equipment was available to the workers in both conditions. However, as previously mentioned, their tool preference differed depending on the task performed.

\subsection{Data analysis}

Postural exposure data were processed as a function of real time according to the Exposure Variation Analysis (EVA) method proposed by Mathiassen and Winkel (1991). The results from this analysis method can be presented in bar diagrams, in which the cumulative time spent continuously in posture and time class limits is presented as a percentage of total working time (Mathiassen and Winkel 1991). Posture class limits were established according to guidelines in the literature. Neck flexion/extension was grouped into six classes of $15^{\circ}$ intervals, ranging from $>15^{\circ}$ of extension to $>45^{\circ}$ of flexion (Chaffin 1973). Upper arm elevation amplitude was grouped into six classes of $30^{\circ}$ intervals, ranging from 0 to more than $150^{\circ}$ of elevation (Bernard 1997, Svendsen et al. 2004, Delleman and Dull 2007). The time spent in different ranges of posture was grouped into five classes according to Jansen et al. (2001) (0-1 s, >1-2 s, >2-5 s, >5-10 s and >10 s). An exposure variation routine for analysis processing was developed in MatLab (v 7.6.0; Math Works Inc., Natick, USA).

The Shapiro-Wilk test was used to determine the normality of the distribution of the data sets. Since the posture exposure and task duration were not normally distributed, the Mann-Whitney test ( $5 \%$ significance) was used to compare the simulated and field conditions. To reduce the chance of type I error to compare simulated and field groups among each class of posture exposure (EVA classes), the False Discovery Rate (Benjamini and Hochberg 1995) was used for $p$-value adjustment. 
Since the age, anthropometric data and years of experience were normally distributed, Student's $t$-test for independent samples ( $5 \%$ significance) was used to compare these variables between simulated and field groups. SPSS 11.5 (SPSS Inc, Chicago, IL, USA) was used for statistical analysis.

To assess the within-subject variability, some subjects performed each task twice during the field recordings. The between-subject variability was evaluated for the 12 workers during field and simulated conditions. Withinand between-subject variability were assessed by means of standard deviation (Hansson et al. 2006). For this analysis, the amplitude probability distribution function (APDF) method was used to reduce the exposure data. The 10th, 50th and 90th percentiles of APDF were used to assess variability. Operational difficulties prevented the double performance of all tasks by all subjects.

\section{Results}

The two groups of workers were similar regarding age $(p=0.07)$, weight $(p=0.09)$, height $(p=0.51)$ and years of experience on the job $(p=0.11)$.

Only the relay replacement task showed significant differences within posture exposure classes between simulated and field conditions (Figure 2). For the consumer connect/disconnect and bulb replacement tasks, the simulated and field conditions presented similar posture exposure (Figures 3 and 4). Although there were not statistically significant differences between the conditions for the consumer connect/disconnect and bulb replacement tasks, visual differences are depicted for all tasks in the results presented.

Figure 2. Exposure variation analysis of neck extension/flexion and upper arm elevation during relay replacement task for simulated ( $N=12$ workers) and field environments ( $N=12$ workers). Statistical significant differences were identified by letter combined with numbers just above the top of each exposure class: letter ' $a$ ' corresponds to the lower limit of posture exposure class and sequentially the exposure runs till letter ' $f$ ' that corresponds to the upper limit of posture exposure class; number ' 1 ' corresponds to lower limit of time class till ' 5 ' that corresponds to the upper limit of time class. 

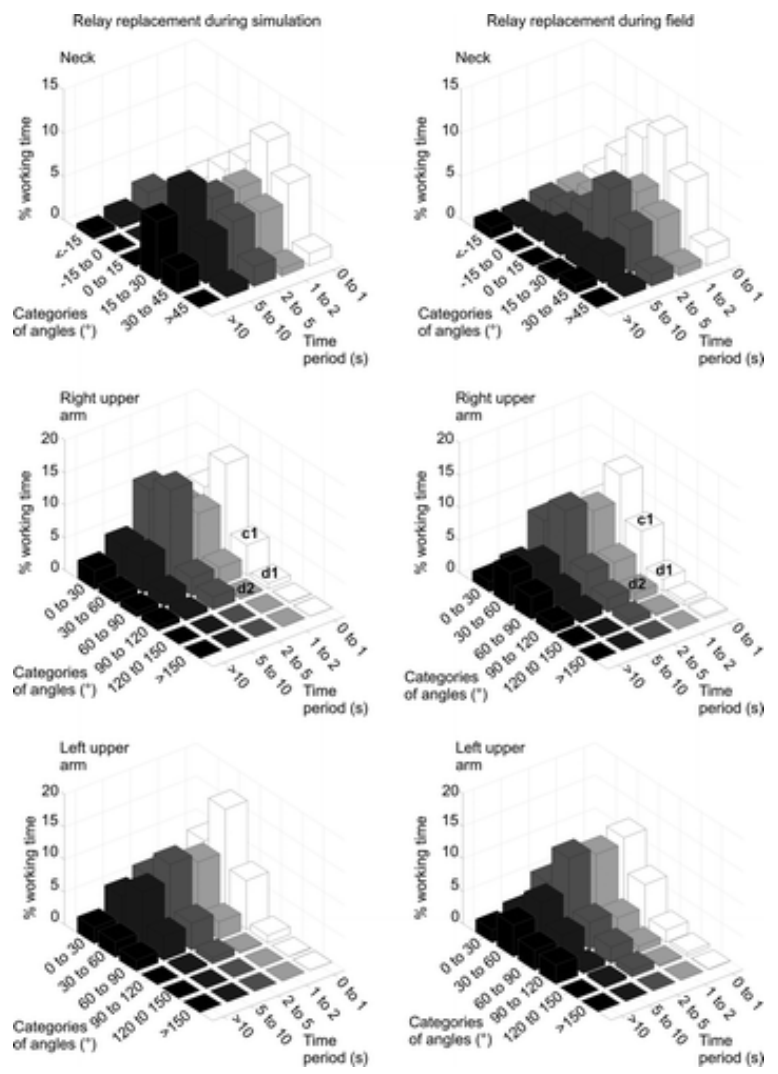

Figure 3. Exposure variation analysis of neck extension/flexion and upper arm elevation during consumer connection/disconnection task for simulated ( $N=12$ workers) and field environments ( $N=11$ workers).
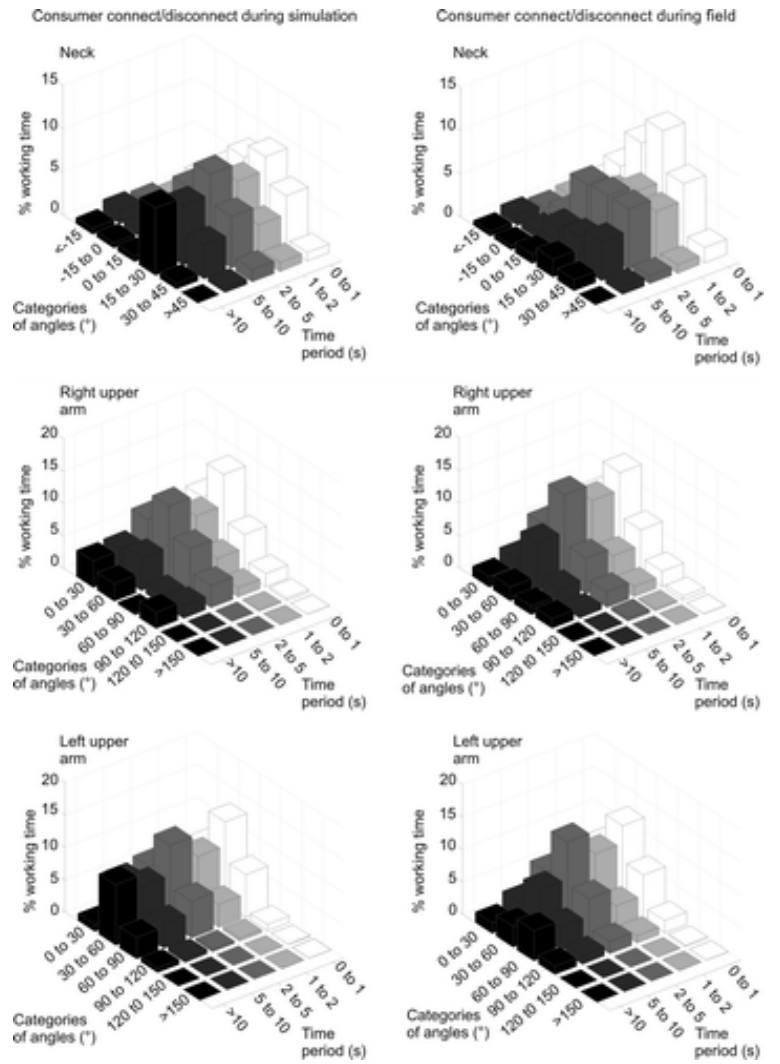

Figure 4. Exposure variation analysis of neck extension/flexion and upper arm elevation during bulb replacement task for simulated ( $N=12$ workers) and field environments ( $N=11$ workers). 

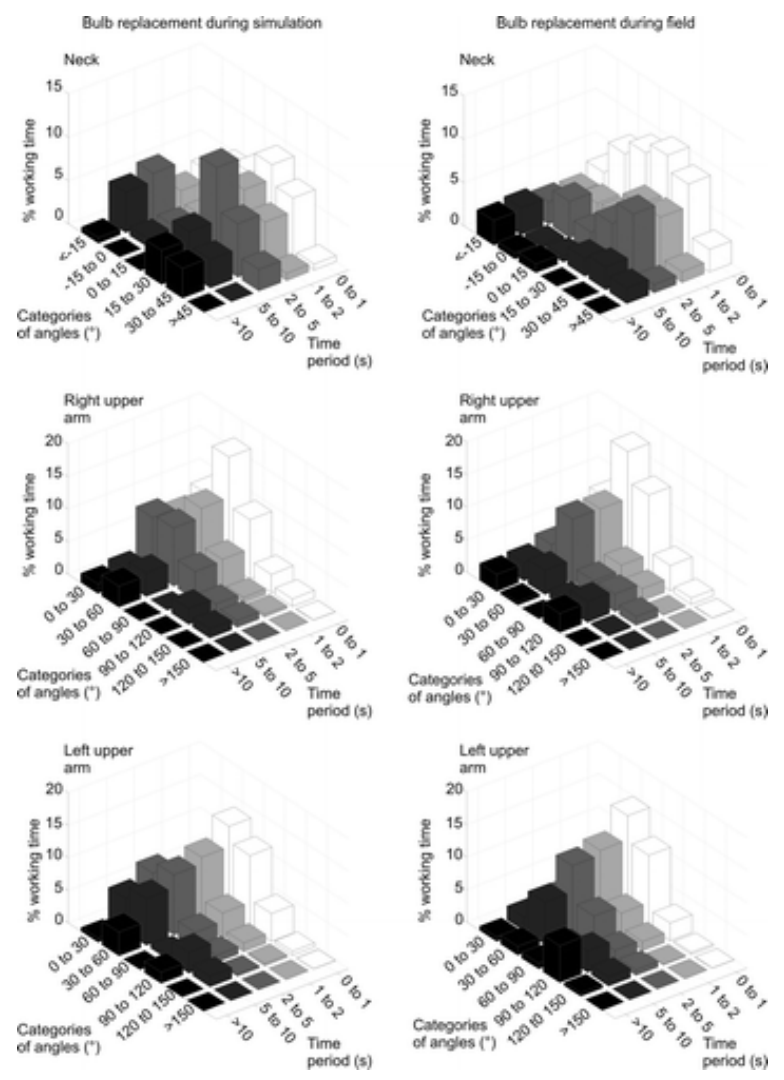

Although the difference was not statistically significant, during the relay task in simulated environment, the workers spent more time at neck posture intervals between $15^{\circ}$ and $45^{\circ}$ of flexion. Aside from more flexed postures, the neck workload was more static during simulation, since there were longer periods in the higher time classes, i.e. unbroken exposure for more than $10 \mathrm{~s}$. On the other hand, during field conditions, work time was more distributed among posture classes in neutral and extended neck postures than during simulated conditions. Along with the higher levels of neck extension in the field environment, higher levels of upper arm elevation were also found in the field. The percentage of work time spent in posture classes above $60^{\circ}$ of the right upper arm elevation in field was statistically higher than in simulated environment.

The neck postures in the simulated consumer connect/disconnect task, like those in the relay task, presented more static workload and a higher percentage of time spent between $15^{\circ}$ and $45^{\circ}$ of neck flexion. More time was spent between $30^{\circ}$ and $60^{\circ}$ of elevation by the left upper arm and lower percentage of time was recorded at elevations above $90^{\circ}$ during simulated conditions when compared with field conditions.

The neck posture in the simulated bulb changing task also involved a higher percentage of time between $15^{\circ}$ and $45^{\circ}$ of neck flexion, but it also involved high percentage of time at extension. Like those in the relay and consumer connect/disconnect tasks, in the field environment, work time was more distributed among neck posture classes. In addition to neck flexion, during simulated conditions, workers also spent more time in lower posture classes of upper arm elevation.

The relay replacement, consumer connection/disconnection and bulb replacement task durations are presented in Table 2. Statistically significant differences between simulated and field conditions were found for relay 
replacement and consumer connection/disconnection task durations, with more time spent in the field than in simulated environments.

Table 2. Mean (M), standard deviation (SD) and difference between the duration of the simulated (S) and field (F) tasks.

\begin{tabular}{|l|c|c|c|c|}
\hline & Task duration (min) & & & \\
\hline & S, M (SD) & F, M (SD) & S - F & Sig \\
\hline Relay replacement & $2.3(0.7)$ & $5.9(1.6)$ & -3.6 & $\mathbf{0 . 0 0 0}$ \\
\hline Consumer connection/disconnection* & $4.3(1.5)$ & $6.8(1.8)$ & -2.5 & $\mathbf{0 . 0 0 4}$ \\
\hline Bulb replacement* & $2.4(0.4)$ & $2.3(0.6)$ & 0.1 & 0.786 \\
\hline
\end{tabular}

Note: Significant differences are presented in bold. *Eleven workers performed the task in field environment.

The highest levels of standard deviation were found for between-subject variability during field conditions for most APDF-percentiles of the relay and bulb replacement tasks (Table 3). During the relay task in field environment, the within-subject variability presented similar or higher values than the between-subject variability during simulated conditions. This fact was not observed for the consumer connection/disconnection or bulb tasks, in which between-subject variability in the simulated environment were higher than withinsubject variability in the field. Within- and between-subject variability values for the consumer connection/disconnection task were relatively similar. 
Table 3. Within- and between-subjects variability of relay replacement, consumer connection/disconnection and bulb replacement tasks calculated for 10th, 50th and 90th percentiles of amplitude probability distribution function (APDF).

\begin{tabular}{|c|c|c|c|c|c|c|c|c|c|}
\hline & $\begin{array}{c}10 \text { th } \\
\text { percentile of } \\
\text { APDF }\left({ }^{\circ}\right) \\
\end{array}$ & & & $\begin{array}{c}50 \text { th } \\
\text { percentile of } \\
\text { APDF }\left({ }^{\circ}\right) \\
\end{array}$ & & & $\begin{array}{c}\text { 90th } \\
\text { percentile of } \\
\text { APDF }\left({ }^{\circ}\right) \\
\end{array}$ & & \\
\hline & Simulated & Field & & Simulated & Field & & Simulated & Field & \\
\hline & $\begin{array}{l}\text { SD between- } \\
\text { subjects }\end{array}$ & $\begin{array}{c}\text { SD } \\
\text { between- } \\
\text { subjects }\end{array}$ & $\begin{array}{l}\text { SD within- } \\
\text { subjects }\end{array}$ & $\begin{array}{l}\text { SD between- } \\
\text { subjects }\end{array}$ & $\begin{array}{c}\text { SD } \\
\text { between- } \\
\text { subjects }\end{array}$ & $\begin{array}{l}\text { SD within- } \\
\text { subjects }\end{array}$ & $\begin{array}{l}\text { SD between- } \\
\text { subjects }\end{array}$ & $\begin{array}{c}\text { SD } \\
\text { between- } \\
\text { subjects }\end{array}$ & $\begin{array}{l}\text { SD within- } \\
\text { subjects }\end{array}$ \\
\hline Relay replacement & $N=12$ & $N=12$ & $N=7$ & $N=12$ & $N=12$ & $N=7$ & $N=12$ & $N=12$ & $N=7$ \\
\hline Neck & 9.8 & 10.9 & 5.9 & 6.7 & 9.7 & 6.3 & 9.7 & 7.1 & 2.4 \\
\hline Right upper arm & 4.8 & 5.8 & 4.7 & 5.6 & 8.8 & 8.7 & 13.0 & 20.9 & 16.1 \\
\hline Left upper arm & 3.7 & 6.9 & 3.6 & 3.4 & 10.3 & 6.5 & 6.5 & 18.3 & 9.8 \\
\hline $\begin{array}{l}\text { Consumer } \\
\text { connection/disconnection }\end{array}$ & $N=12$ & $N=11$ & $N=3$ & $N=12$ & $N=11$ & $N=3$ & $N=12$ & $N=11$ & $N=3$ \\
\hline Neck & 11.5 & 7.7 & 3.5 & 8.1 & 6.5 & 5.8 & 9.8 & 6.7 & 6.8 \\
\hline Right upper arm & 5.3 & 5.3 & 2.3 & 6.8 & 7.2 & 5.5 & 14.7 & 16.4 & 18.0 \\
\hline Left upper arm & 4.8 & 5.4 & 4.5 & 7.2 & 7.5 & 4.1 & 10.0 & 12.1 & 12.5 \\
\hline Bulb replacement & $N=12$ & $N=11$ & $N=3$ & $N=12$ & $N=11$ & $N=3$ & $N=12$ & $N=11$ & $N=3$ \\
\hline Neck & 10.0 & 16.2 & 6.4 & 6.4 & 13.3 & 4.9 & 8.9 & 8.9 & 3.0 \\
\hline Right upper arm & 6.5 & 5.9 & 5.6 & 7.4 & 9.6 & 2.5 & 15.6 & 12.3 & 15.5 \\
\hline Left upper arm & 3.5 & 7.4 & 4.0 & 5.7 & 11.6 & 4.4 & 12.7 & 18.1 & 13.2 \\
\hline
\end{tabular}




\section{Discussion}

Of the three evaluated overhead tasks, two (consumer connection/disconnection and bulb replacement) allowed a more representative evaluation of work postural exposure under simulated conditions. However, for the relay replacement task, the postures in the experimental conditions underestimated the postural exposure recorded in the real occupational settings for the right upper arm.

Significant differences between field and simulated postural exposure were found for the relay replacement task, indicating that the simulated conditions provided for this task did not accurately reproduce field posture exposure. The differences found between the two conditions seem to be explained by the extra subtasks that the relay replacement task requires in field (Table 1). In the field environment, all overhead workers must perform at least one extra subtask during relay replacement, e.g. relay testing and wire connection. The need to perform these extra subtasks also led to the differences in task duration in the simulated (shorter) and field environment (Table 2). The higher levels of within-subject variability in field environment than between-subject variability found in simulated environment could also be explained by the extra subtasks performed in the real settings. Thus, for the relay replacement task, the simulated conditions were not representative of the field conditions due to the lack of customary extra subtasks.

One possibility for solving these differences and allowing for a more precise comparison between the simulated and field conditions would be to exclude the extra subtasks from the relay replacement task for data analysis. However, since the extra subtasks were short (10-30 s), it was impractical to accurately distinguish the specific subtasks from the extra subtasks, since the researcher was annotating the subtasks during data collection. This is particularly important considering that the recording of the work activities lasted more than $3 \mathrm{~h}$ per worker.

In the context of more complex tasks, the simulated environment was simplified, omitting variations of setting and the extra subtasks present in the field. It is still a challenge to reproduce some tasks in simulated environments when they involve very short and non-cyclical subtasks or occur in varied or more complex occupational contexts. As a consequence, differences between simulated and field results can be expected. Thus, the outcomes from simulated studies, reproducing more complex tasks, should be considered in the light of this understanding. Leaving out subtasks that appear to be inconsequential may significantly interfere with the objectives of the laboratory simulation and therefore give erroneous results.

For the consumer connection/disconnection and bulb replacement tasks, the time spent working in each postural exposure class was similar between simulated and field environments. Because these tasks were more standardised and involved fewer extra subtasks, better representativeness was achieved in simulated settings. The depicted differences between the conditions for these tasks could be explained by the workstation setup. In the simulated environment, the focus of the activities was in front of the subject. However, for most activities in the field, the position of the activities varied (see setup description in Table 1). This fact might also explain the more static and flexed neck postures and lower levels of upper arm elevation presented by the workers in simulated environment.

When comparing exposure differences between conditions, the natural variability between days and subjects should be noted. Hansson et al. (2006) found a mean within-subject variability of $4.5^{\circ}$ for neck posture and $3.8^{\circ}$ for upper arm elevation, as well as a between-subject variability of $4.4^{\circ}$ for the neck and $4.5^{\circ}$ for the upper arms during standardised tasks performed in a laboratory setting. These authors recorded the postures using inclinometry and the ADPF data reduction method. Wahlström et al. (2010) recorded the upper arm elevation of hairdressers in an occupational environment on four days to evaluate postural variability. In this study, higher levels of within- and between-subject variability were reported $\left(5.5^{\circ}\right.$ and $7.5^{\circ}$, respectively, for the 90th APDF- 
percentile of right upper arm elevation). According to Hansson et al. (2006), greater variability values can be expected in field environment than in a simulated setting, since real work conditions cannot be standardised.

The variability found for the three evaluated tasks was higher than other reports in the literature. The withinsubject variability presented a standard deviation of up to $18^{\circ}$ in the field conditions, which means that even when the same worker performs the same task, postures can vary widely. The within-subject variability in field environment was even higher than between-subject variability during simulated conditions, which highlights the complexity of the tasks and postural exposure in real occupational settings. This complexity indicates that more attention should be paid by both companies when simulating training environments for their workers and researchers when planning to simulate the conditions of complex tasks.

The results of the present study revealed the same trends that have been reported in other studies comparing simulated and field measurements. Oldham et al. (2000) evaluated simulated firefighter activities to assess muscle activity. According to their results, the differences between the conditions also varied according tasks. However, simulated results may under- or overestimate load.

Assessing the representativeness of overload in simulated environments is important in order for the practitioners to apply the research results (Filippin and Wagner 2008, Chung and Shorrock 2011), which is essential for Ergonomics as an applied discipline (Buckle 2011, Dul et al. 2012). Thus, considering the methodological advantages of controlled settings for data collection (Westgaard and Winkel 1997, Scott and Renz 2006), i.e. less time and less interference with data collection, simulating work conditions would seem to be a practical and reasonable approach for measuring the postural data of overhead utility workers performing more standardised tasks. In addition, this issue is particularly relevant for these workers, whose work regulations specify that part of their training and periodic retraining must be performed in simulated settings due to safety reasons.

\subsection{Study limitations}

The subtasks involved in the relay replacement task were not included in the simulated environment and procedures, which led to underestimation of the postural exposure and complexity of the real occupational situation. In order to properly reproduce work conditions in experimental settings for either worker training or research, it is advisable that all subtasks be carefully reproduced in the simulated settings. Failure to consider the complexity of a task could compromise the overload reproduction.

Another limitation of this study is that the workers performed only one trial of each task in the simulated environment. Furthermore, it was not possible to have all the workers perform a complete set of tasks twice in the field environment, which limited the evaluation of within-subject variability.

\section{Conclusions}

The results indicated that simulated conditions may be more representative of postural exposure for more standardised tasks performed in the field by overhead electric workers. Omitting extra subtasks from complex tasks during simulated conditions may interfere with the results and led to an inaccurate and underestimated posture exposure.

\section{Acknowledgements}

The authors thank the following agencies for partial financial support: the Coordination for the Improvement of Higher Education Personnel (CAPES/PNPD, Process Number 23038.006938/2011-72), the São Paulo Research Foundation (FAPESP, Process Number 2008/10372-4 and 2008/10399-0) and the National Counsel of Technological and Scientific Development (CNPq, Process Number 301772/2010-0). 


\section{References}

Benjamini, Y. and Hochberg, Y. 1995. Controlling the false discovery rate: a practical and powerful approach to multiple testing. Journal of the Royal Statistical Society, 57(1): 289-300.

Bernard, B.P. 1997. "Musculoskeletal disorders and workplace factors". In A critical review of epidemiologic evidence for work-related musculoskeletal disorders of the neck, upper extremity, and low back, 97141. Washington, DC: NIOSH. DHHS (NIOSH) Publication No.

Buckle, P. 2011. 'The perfect is the enemy of the good' - ergonomics research and practice. Institute of Ergonomics and Human Factors Annual Lecture 2010. Ergonomics, 54(1): 1-11.

Chaffin, D.B. 1973. Localized muscle fatigue - definition and measurement. Journal of Occupational Medicine, 15(4): 346-354.

Chung, A.Z.Q. and Shorrock, S.T. 2011. The research-practice relationship in ergonomics and human factors surveying and brindging the gap. Ergonomics, 54(5): 413-429.

David, G.C. 2005. Ergonomics methods for assessing exposure to risk factors for work-related musculoskeletal disorders. Occupational Medicine, 55(3): 190-199.

Delleman, N.J. and Dull, J. 2007. International standards on working postures and movements ISO11226 and EN 1005-4. Ergonomics, 50(11): 1809-1819.

Dul, J., Bruder, R., Buckle, P., Carayon, P., Falzon, P., Marras, W.S., Wilson, J.R. and van der Doelen, B. 2012. A strategy for human factors/ergonomics: developing the discipline and profession. Ergonomics, 55(4): 377-395.

Electric Power Research Institute (EPRI). Occupational health and safety annual report 2011: occupational health and safety injury surveillance among electric energy workers, 1995-2010. Palo Alto, CA: EPRI.

Filippin, L.I. and Wagner, M.B. 2008. Evidence based physical therapy: a new perspective. Brazilian Journal of Physical Therapy, 12(5): 432-433.

Hansson, G.-Å., Asterland, P., Holmer, N.-G. and Skerfving, S. 2001. Validity and reliability of triaxial accelerometers for inclinometry in posture analysis. Medical \& Biological Engineering \& Computing, 39(4): 405-413.

Hansson, G.Å., Arvidsson, I., Ohlsson, K., Nordander, C., Mathiassen, S.E., Skerfving, S. and Balogh, I. 2006. Precis ion of measurements of physical workload during standardised manual handling. Part II: Inclinometry of head, upper back, neck and upper arms. Journal of Electromyography and Kinesiology, 16(2): 125-136.

Hansson, G.Å., Balogh, I., Ohlsson, K., Granqvist, L., Nordander, C., Arvidsson, I., Åkesson, I., Unge, J., Rittner, R., Strömberg, U. and Skerfving, S. 2010. Physical workload in various types of work: part II. Neck, shoulder and upper arm. International Journal of Industrial Ergonomics, 40(3): 267-281.

Jansen, J.P., Burdorf, A. and Steyerberg, E. 2001. A novel approach for evaluating level, frequency and duration of lumbar posture simultaneously during work. Scandinavian Journal of Work, Environment \& Health, 27(6): 373-380.

Mathiassen, S.E. and Winkel, J. 1991. Quantifying variation in physical load using exposure-vs-time data. Ergonomics, 34(12): 1455-1468.

Moriguchi, C.S., Alencar, J.F., Miranda Junior, L.C. and Gil Coury, H.J.C. 2009. Musculoskeletal symptoms among energy distribution network linemen. Brazilian Journal of Physical Therapy, 13(2): 123-129.

Moriguchi, C.S., Carnaz, L., Alencar, J.F., Miranda, L.C. Jr, Granqvist, L., Hansson, G.-Å. and Gil Coury, H.J.C. 2011. Postures and movements in the most common tasks of power line workers. Industrial Health, 49(4): 482-491.

Oldham, J.A., Schofield, S., Callaghan, M.J. and Winstanley, T. 2000. An investigation of the validity of 'simulated' work related tasks in relation to 'real life' situations in the fire service training environment. Occupational Medicine, 50(8): 599-607.

Oliveira, A.B., Silva, L.C.C.B. and Coury, H.J.C.G. 2011. How do low/high height and weight variation affect upper limb movements during manual material handling of industrial boxes?. Brazilian Journal of Physical Therapy, 15(6): 494-502.

Petruzzello, S.J., Gapin, J.I., Snook, E. and Smith, D.L. 2009. Perceptual and physiological heat strain: examination in firefighters in laboratory- and field-based studies. Ergonomics, 52(6): 747-754. 
Rodack, A.L.F. and Vieira, J.E. 2010. The effect of different supermarket checkout workstation on trunk kinematics of checkout operators. Brazilian Journal of Physical Therapy, 14(1): 39-44.

Salmon, P.M., Stanton, N.A., Walker, G.H., Jenkins, D., Baber, C. and McMaster, R. 2008. Representing situation awareness in collaborative systems: a case study in the energy distribution domain. Ergonomics, 51(3): 367-384.

Scott, P.A. and Renz, M.C. 2006. A combined field and laboratory investigation for the effective application of ergonomics in situ. Applied Ergonomics, 37(6): 785-792.

Seeley, P.A. and Marklin, R.W. 2003. Business case for implementing two ergonomic interventions at an electric power utility. Applied Ergonomics, 34(5): 429-439.

Svendsen, S.W., Bonde, J.P., Mathiassen, S.E., Stengaard-Pedersen, K. and Frich, L.H. 2004. Work-related shoulder disorders: quantitative exposure-response relationships with reference to arm posture. Occupational and Environmental Medicine, 61(10): 844-853.

van Dieën, J.H., Faber, G.S., Loos, R.C.C., Kuijer, P.P.F.M., Kingma, I., van der Molen, H.F. and FingsDresen, M.H.W. 2010. Validity of estimates of spinal compression forces obtained from worksite measurements. Ergonomics, 53(6): 792-800.

Wahlström, J., Mathiassen, S.E., Liv, P., Hedlund, P., Ahlgren, C. and Forsman, M. 2010. Upper arm postures and movements in female hairdressers across four full working days. The Annals of Occupational Hygiene, 54(5): 584-594.

Westgaard, R. and Winkel, J. 1997. Ergonomic intervention research for improved musculoskeletal health: a critical review. International Journal of Industrial Ergonomics, 20(6): 463-500.

Winkel, J. and Mathiassen, S.E. 1994. Assessment of physical work load in epidemiologic studies: concepts, issues and operational considerations. Ergonomics, 37(6): 979-988

Winkel, J. and Westgaard, R. 1992. Occupational and individual risk factors for shoulder-neck complaints: part II - The scientific basis (literature review) for the guide. International Journal of Industrial Ergonomics, 10(1-2): 85-104. 